Check for updates

Cite this: RSC Adv., 2017, 7, 31485

\title{
Study on a novel high energetic and insensitive munitions formulation: TKX-50 based melt cast high explosive
}

\author{
Yuehai Yu, (D) a Shusen Chen, ${ }^{a}$ Tujuan Li, ${ }^{a}$ Shaohua Jin, (D) a Guangyuan Zhang, ${ }^{b}$ \\ Minglei Chen ${ }^{\mathrm{b}}$ and Lijie Li*a
}

Dihydroxylammonium 5, $5^{\prime}$-bistetrazole-1,1'-diolate (TKX-50) is a promising candidate to replace traditional explosives, 1,3,5,7-tetranitro-1,3,5,7-tetraazacyclooctane (HMX) and 1,3,5-trinitroperhydro-1,3,5-triazine (RDX), used in insensitive munitions, which is currently being explored to achieve shock insensitive melt cast formulations. Safety and energetic properties of melt cast explosive formulations help in implementing applications in the future. In the present study, TKX-50 based melt cast formulations are prepared with 2,4,6-trinitrotoluene (TNT) as a dispersant. Furthermore, the safety assessment and energy performance are studied along with HMX based melt cast formulations for comparison. In order to gain insight into the coating mechanism, the interaction energies calculations were performed at the B3LYP/ 6-311G** level. The results revealed that stronger attractive forces exist in TKX-50-TKX-50 than in HMX-HMX pairs and similarly in TKX-50-TNT than in HMX-TNT, which have good agreement with the coating conditions. This comparative study reveals that the safe and energy performance of TKX-50 based formulations is superior to HMX based formulations.

Received 8th May 2017

Accepted 15th June 2017

DOI: $10.1039 / c 7 r a 05182 d$

rsc.li/rsc-advances
CL-20, but its production costs are less than CL-20. On the account of good performance in sensitivity and energy, TKX-50 becomes one of the most valuable energetic materials for application in current stage.

In order to explore the application of TKX-50 in explosive, propellant and pyrotechnics in the future, its safety performance and energy property study are of great interest by researchers. Sinditskii V. P. et al. have studied the combustion behavior and physico-chemical properties of TKX-50. ${ }^{18} \mathrm{Y}$. Yu et al. have simulated TKX-50 based PBXs with four kinds of polymer binders. ${ }^{19} \mathrm{H}$. Niu et al. have studied the thermal risk evaluation of TKX-50 based PBX. ${ }^{20}$ However, to the best of our knowledge, there is no report on the thermal behaviors, the detonating performance, the safety properties and the theoretical calculations about the formulations of TKX-50. TKX-50 has not been explored to melt cast high explosive.

Herein, to investigate the safety and risk properties of TKX50 based melt cast explosive, we choose HMX as the comparison due to TKX-50 has been evaluated as a possible replacement for HMX in TNT based melt cast formulations. In the present paper, the loading of TNT in the formulations has been restricted to a maximum of $40 \%$ by weight in non-paraffin wax formulations and a maximum of $30 \%$ by weight in paraffin wax formulations, which are the same both in TKX-50 and HMX based formulations. The formulations have been characterized for their thermal decomposition behavior, sensitivity to mechanical stimuli, velocity of detonation (VOD) and theoretical calculation. The research was aimed at optimizing TKX-50
${ }^{a}$ School of Material Science and Engineering, Beijing Institute of Technology, 100081 Beijing, China.E-mail: lilijie2003@bit.edu.cn

${ }^{b}$ Research Institute of Gansu Yin'guang Chemical Industry Group Baiyin, 730900, P. R. China 
and TNT based melt cast formulations and at generating initial data for exploring these formulations as insensitive high explosive formulations for future applications in insensitive munitions.

\section{Experimental details}

\subsection{Explosive formulations}

The TKX-50 based melt cast formulations, non-paraffin wax and paraffin wax formulations, are named TT and TTW respectively, as well as HMX based melt cast formulations are named HT and HTW. The subjects above are summarized in Fig. 1.

\subsection{Processing of the explosive formulations}

The compositions were processed by the standard, melt-cast technique involving the addition of TKX-50 and HMX to molten TNT, with continuous stirring in a steam jacketed anchor blade mixer. This was followed by the addition of paraffin wax to the melt (in the wax formulations TTW and HTW). The mixture was stirred for about 10-15 minutes and then transferred to a mould. After cooling to ambient conditions, the charge was extracted and machined to the required dimensions.

\section{Characterizations/evaluations}

\subsection{Thermal decomposition study by DSC}

The thermal decomposition studies of the four formulations TT, HT, TTW and HTW were carried out by using the technique of Differential Scanning Calorimeter (DSC, Mettler-Toledo, aluminium pan with a pin hole cover in dynamic nitrogen

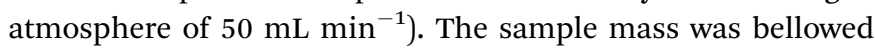
$1 \mathrm{mg}$ with a heating rate of $1,2,5$ and $10^{\circ} \mathrm{C} \mathrm{min}^{-1}$ (temperature range: $50-350{ }^{\circ} \mathrm{C}$ ).

\subsection{Scanning electronic microscopy (SEM)}

Scanning electronic microscope TESCAN MIRA3XMU (Chech) has been used to investigate the structure of the formulations and the pure explosives upper layers. Potential difference of electron acceleration was $5.0 \mathrm{kV}$. The signal detection is secondary electron.

\subsection{Powder X-ray diffraction (PXRD)}

Powder X-ray diffraction (PXRD) data of the four formulations TT, HT, TTW and HTW were collected at room temperature on
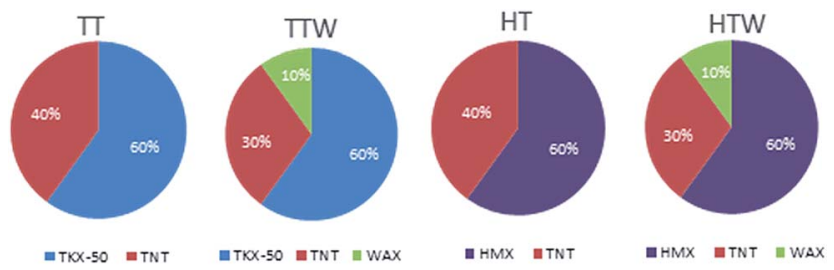

Fig. 1 Pie charts showing the percentage of TKX-50 and HMX based formulations. a Rigaku Ultima IV X-ray diffractometer (CuK $\alpha$ radiateon, $40 \mathrm{kV}$ tube voltage, $44 \mathrm{~mA}$ current). The $2 \theta$ range measured was $5-50^{\circ}$ with steps of $0.02^{\circ} / 0.1 \mathrm{~s}$.

\subsection{Determination of mechanical sensitivity parameters}

The impact sensitivity of the four formulations was recorded with impact instrument according to the Chinese Military Standards GJB 772A-97 Method 601.2. The testing conditions were as follows: drop weight, $5 \mathrm{~kg}$; sample mass, $50 \mathrm{mg}$. The result of impact sensitivity was given in terms of the statistically obtained $50 \%$ probability of explosion $\left(H_{50}\right)$.

\subsection{Determination of the heat sensitivity parameters}

The heat sensitivity was indicated by the $5 \mathrm{~s}$ delay explosion temperature according to the Chinese Military Standards GJB 772A-97 Method 606.1.

The delay explosion $t$ and temperature of explosion $T$ uses the following equations of state, in the form:

$$
\begin{aligned}
t & =C \mathrm{e}^{E / R T} \\
\ln t & =\frac{E}{R T}+\ln C
\end{aligned}
$$

where $t$ is the value of delay explosion in $\mathrm{s}, C$ is a constant related the tested material component, $E$ is the value of apparent activation energy of the tested material in $\mathrm{J} \mathrm{mol}^{-1}, R$ is gas constant of molar $\left(8.314 \mathrm{~J}\left(\mathrm{~mol}^{-1} \mathrm{~K}^{-1}\right)\right), T$ is values about temperature of explosion in $\mathrm{K}$.

\subsection{Determination of the specific heat capacity}

The normal method for determination of specific heat capacity by DSC in the continuous mode was well established. The heating rate was $10{ }^{\circ} \mathrm{C} \mathrm{min}^{-1}$, and the high purity nitrogen gas was used as purifying gas, whose flowing rate was $20 \mathrm{~mL}$ $\min ^{-1}$

The heat flow rate into the sample is related to the specific heat capacity of sample and the relation is given by ref. 21 .

$$
\frac{\mathrm{d} H}{\mathrm{~d} t}=m C_{\mathrm{p}} \frac{\mathrm{d} T}{\mathrm{~d} t}
$$

where $\mathrm{d} H / \mathrm{d} t$ is the heat flow rate in $\mathrm{J} \mathrm{min}^{-1}, m$ is the sample mass in $\mathrm{g}, C_{\mathrm{p}}$ is the specific heat capacity in $\mathrm{J}\left(\mathrm{g}^{-1}{ }^{\circ} \mathrm{C}\right), \mathrm{d} T / \mathrm{d} t$ is the heating rate in ${ }^{\circ} \mathrm{C} \mathrm{min}^{-1}$. From which we can see the heat flow rate is in direct proportion to the specific heat capacity of sample. From eqn (3) we can get:

$$
\frac{C_{\mathrm{p}}}{C_{\mathrm{p}}^{\prime}}=\frac{m^{\prime} \Delta Y}{m \Delta Y^{\prime}}
$$

where $\Delta Y^{\prime}$ and $\Delta Y$ are the ordinate deflections due to the standard and the sample, $C_{\mathrm{p}}^{\prime}$ and $C_{\mathrm{p}}$ are the specific heat capacity of the standard and sample, $m^{\prime}$ and $m$ are the mass and specific heat capacity of standard and sample, respectively.

\subsection{Determination of the vacuum stability test}

The vacuum stability test was carried out according the Chinese Military Standards GJB 772A-97 Method 601.2. The testing 
conditions were as follows: sample mass, $5.00 \pm 0.01 \mathrm{~g}$; testing temperature, $100.0 \pm 0.5{ }^{\circ} \mathrm{C}$; heating time, $48 \mathrm{~h}$. The testing was measured three times in the same conditions.

In standard condition, the volume of the sample released was calculated by the eqn (5)

$$
V_{\mathrm{H}}=2.69 \times 10^{-3} \times \frac{P}{T}\left(V_{\mathrm{O}}-V_{\mathrm{G}}\right)
$$

where $V_{\mathrm{H}}$ is the volume of the sample released in standard condition in $\mathrm{mL}, 2.69 \times 10^{-3}$ is the ratio of temperature and pressure in $\mathrm{K} \mathrm{Pa}^{-1}, P$ is the pressure of the sample released in $\mathrm{Pa}, V_{\mathrm{O}}$ is the sum of the volume of the reactor and the volume of the connecting pipe in $\mathrm{mL}, V_{\mathrm{G}}$ is the volume of the sample in $\mathrm{mL}$ and $T$ is the temperature of the testing in ${ }^{\circ} \mathrm{C}$.

\subsection{Thermal studies under non-isothermal conditions}

Kissinger $^{22}$ and Flynn-Wall-Ozawa ${ }^{23}$ methods, described in following eqn (6) and (7), respectively, would be more suitable owing to deriving from the basic kinetic equations for heterogeneous chemical reactions, ${ }^{24}$ according to the International Confederation for Thermal Analysis and Calorimetry (ICTAC) Kinetics Committee ${ }^{25}$ recommendations for performing kinetic computations on thermal analysis data. To determine the kinetic parameters of the matchhead composition, Ozawa and Kissinger's methods were applied.

Kissinger method (differential method):

$$
\ln \left[\frac{\beta}{T_{\mathrm{p}}^{2}}\right]=\ln \left[\frac{A_{\mathrm{K}} R}{E_{\mathrm{K}}}\right]-\frac{E_{\mathrm{K}}}{R T_{\mathrm{p}}}
$$

Flynn-Wall-Ozawa method (integral method):

$$
\lg \beta=\lg \left[\frac{A_{\mathrm{O}} E_{\mathrm{O}}}{R G(\alpha)}\right]-2.315-0.4567 \frac{E_{\mathrm{O}}}{R T_{\mathrm{p}}}
$$

where $\beta$ is the heating rate, $T_{\mathrm{p}}$ is the peak temperature of DSC curve, $A_{\mathrm{K}}$ and $A_{\mathrm{O}}$ are the pre-exponential factor, $E_{\mathrm{K}}$ and $E_{\mathrm{O}}$ are the apparent activation energy determined by Kissinger and Ozawa methods, respectively; $R$ is the gas constant, $\alpha$ is the conversion degree, which is the mass ratio of the reacted substance to the raw, and $G(\alpha)$ is the integral mechanism function. The pre-exponential factor $(A)$ can be computed from the following relation.

$$
A=\frac{\beta \times E_{\alpha} \times \mathrm{e}^{\left(E / R T_{\mathrm{p}}\right)}}{R \times T_{\mathrm{p}}{ }^{2}}
$$

\subsection{Theoretical calculation}

Density functional theory (DFT) ${ }^{\mathbf{2 6 , 2 7}}$ calculations were employed in order to calculate the interaction energies of different ingredients viz. dimers of TKX-50, HMX and TNT along with TKX-50-TNT and HMX-TNT. The geometries of the molecules under investigation were fully optimized without any symmetry restriction at the B3LYP/6-311G(d, p) level by Gaussian 09 software package. ${ }^{28}$ All of the optimized structures were characterized to true local energy minima on the potential-energy surface without imaginary frequencies. Interaction energy (IE) was calculated as follows:

$$
\begin{aligned}
\mathrm{IE}_{(\text {explosive })}= & E_{(\text {explosive dimer })}+E_{(\mathrm{BSSE})} \\
& -\left[E_{(\text {explosive A) }}+E_{(\text {explosive B })}\right]
\end{aligned}
$$

Molecular electrostatic potential were computed for the optimized geometries at the same level of theory.

\section{Results and discussion}

\subsection{XRD analysis}

In order to testify that the crystal type of TKX-50 and HMX did not change during the melting process in TNT for the TT and HT formulations and in TNT/Wax for the TTW and HTW formulations, the crystallinity of pure TKX-50, HMX, TNT and four formulations of TT, HT, TTW and HTW was measured by XRD showing in Fig. 2.

In the XRD, it can be concluded that firstly both TKX-50, HMX and TNT exist in the according formulations of TT and TTW, respectively. Secondly, the crystal forms of both TKX-50 and HMX are not influenced significantly by the melting processing. Because the three characteristic peaks of the explosives TKX-50, HMX and TNT can be found in the corresponding formulations (shown in Fig. 2).

\subsection{SEM analysis}

The SEM images of pure TKX-50, HMX and the four formulations TT, TTW HT and HTW are shown in Fig. 3, where an obvious difference between the pure materials and the four formulations, respectively, on the surface morphology.

The SEM image of the formulations reveals that the crystal of TKX-50 can be coated by the melted TNT comparing the formulation of TT (Fig. 3b) with pure TKX-50 (Fig. 3a), and we can also see that there are few TKX-50 crystals exposed on the surface. As shown in the Fig. 3c, it clearly discloses that almost no crystals can be found outside surface of the composite of TTW, which can indicate that the wax can make a difference on the coating of TKX-50 with TNT. Moreover, the formulations of HMX have the same regular, which can also show that the coating effect can be improved with the addition of paraffin wax. Comparing Fig. 3b with Fig. 3e, we can see intuitively that more crystals are not coated in the formulation of HT than that of TT, which implies that the binding ability between TKX-50 and TNT is stronger than HMX and TNT.
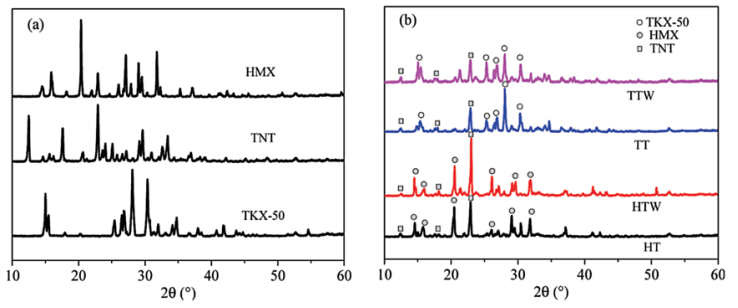

Fig. 2 XRD patterns of pure TKX-50, HMX, TNT (a) and four formulations of TT, HT, TTW and HTW (b). 


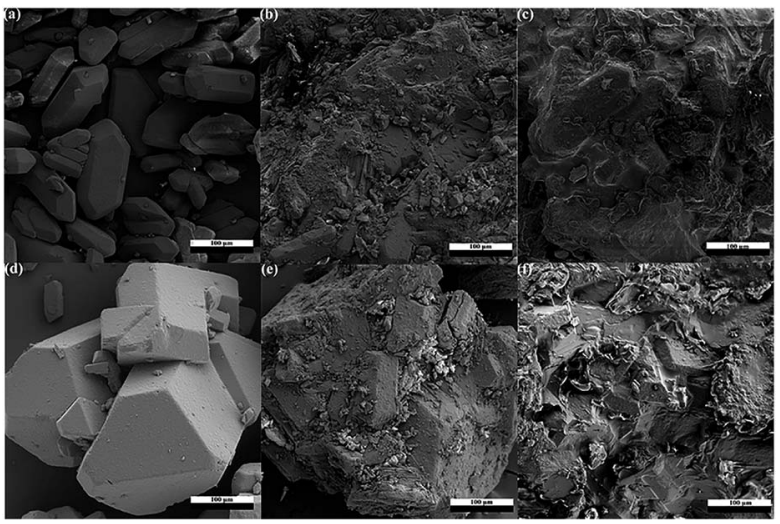

Fig. 3 SEM images of pure TKX-50, HMX and four formulations of (a) TKX-50; (b) TT; (c) TTW; (d) HMX; (e) HT; (f) HTW.

\subsection{DSC studies}

The samples were packaged in an aluminium pan with a pin hole and measurements were performed under the same conditions for all formulations. The DSC curves of the four formulations are carried out at the various heating rate of 1, 2, 5 and $10{ }^{\circ} \mathrm{C} \min ^{-1}$ in Fig. 4 respectively.

According to Fig. 4, we can see the curves of TKX-50 based formulations have an endothermic peak in the temperature range between 79.0 and $86.8^{\circ} \mathrm{C}$, which is caused by the melting of TNT. There is no reaction measured in the temperature range between 87.0 and $213.8^{\circ} \mathrm{C}$. After that a sharp single exothermic peak is observed until $254.7^{\circ} \mathrm{C}$ and a small exothermic peak is detected until $309.3{ }^{\circ} \mathrm{C}$ under various heating rate. The thermal decomposition curves of TKX-50 based formulations are as similar as HMX based formulations. DSC curves of HMX based formulations also have an endothermic peak in the temperature range between 79.0 and $82.1^{\circ} \mathrm{C}$, which is the melting of TNT and an exothermic peak in the temperature range between 263.8 and $288.9^{\circ} \mathrm{C}$.

Onset and peak temperatures of the four formulations are simultaneously increased and released more heat energy at higher heating rates (Fig. 5). When $\beta$ is high, the thermal event is detected at a high temperature. On another front, the heating
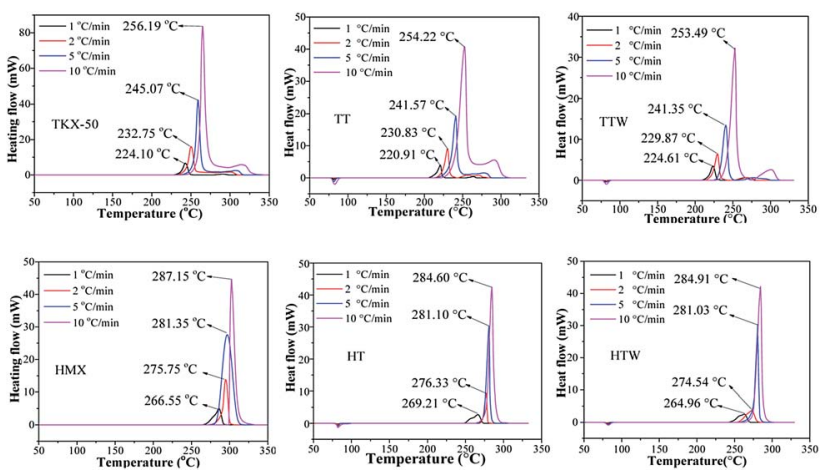

Fig. 4 The thermal decomposition of the four formulations at different heating rates.

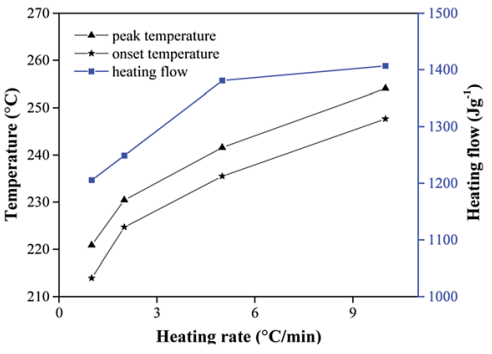

Fig. 5 The relation of onset temperature, peak temperature and heating flow at different heating rate (TT).

rate is low, both the onset temperature $\left(T_{\mathrm{o}}\right)$ and the corresponding peak temperature $\left(T_{\mathrm{p}}\right)$ appear in a lower temperature with a decrease in the heat of reaction. This obvious reason is the kinetics of the process which is a function of temperature and time. Therefore, the $T_{\mathrm{o}}$ and $T_{\mathrm{p}}$ shifted to a higher temperature with a considerable in the heat of reaction. The change of the heating rate maybe cause the change in onset temperature, overlapping and pausing of thermo kinetic events observes, especially, the change of the heat of reaction. Variation in the heat of reaction means changes in the degree of reactivity during specific time duration. In the context of high energetic materials, the generation of heat (self-heating exothermic process) is almost due to the initial concentration and degree of reaction which in this case once initiated would reach $100 \%$ completion. The observed discrepancies may further be due to instrumentation effects. ${ }^{29}$

From the Fig. 4, we can see the peak temperature of the exothermic peaks have little change comparing the formulations of TT and TTW, which is same as the formulations of HT and HTW. This phenomenon illustrates that the paraffin wax is suitable for these formulation and compatibility with TKX-50 and HMX.

Fig. 6 shows the Ozawa and Kissinger plots for the decomposition of the four formulations (TT, TTW, HT, HTW). A linear dependence of the $1 / T_{\mathrm{p}}$ on the $\log \beta$ and $\log \left(\beta /\left(\beta / T_{\mathrm{p}}{ }^{2}\right)\right)$ was
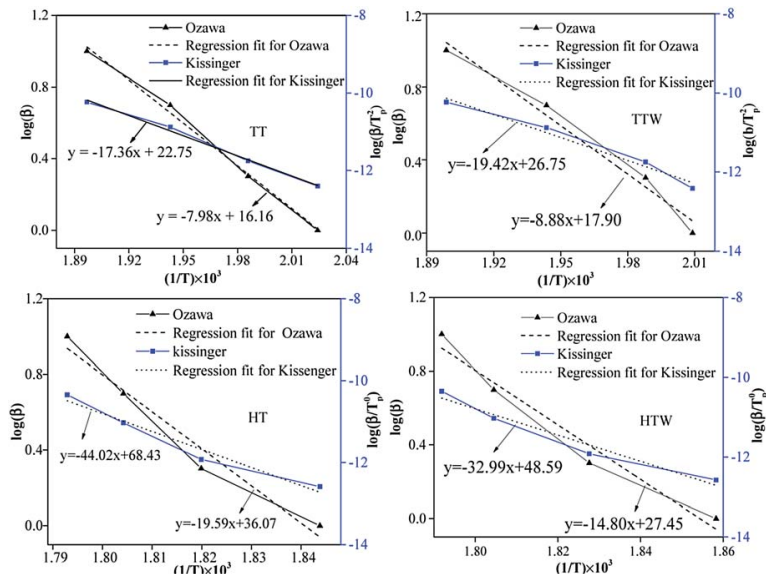

Fig. 6 Ozawa and Kissinger kinetic plots for four formulations thermal decomposition. 
observed and the correlation constants for the two plots were 0.99 and 0.99 of TT, respectively indicating the goodness of fit. The activation energy $\left(E_{\mathrm{a}}\right)$ was calculated from the slope of the straight line obtained by linear regression and the preexponential factor $(A)$ was determined from the eqn (8). The results are shown in Table 1.

As can be seen from the data in Table 1, the fairly close agreement of activation energy of $148 \pm 0.5 \mathrm{~kJ} \mathrm{~mol}^{-1}$ and $149 \pm$ $0.4 \mathrm{~kJ} \mathrm{~mol}^{-1}$ for pure TKX-50, respectively by Kissinger and Ozawa's methods, demonstrates that these methods discussed here could be satisfactorily employed for evaluating the kinetics of the other formulations. They are in the normal range of kinetic parameters for the thermal decomposition reaction of the solid materials. ${ }^{30}$ In Table 1, the activation energy of pure TKX-50, calculating by Kissinger's method, is roughly the same as that of the TKX-50/TNT formulation, but the activation energy of TKX-50/TNT/Wax raises up. The change could be resulted from the addition of paraffin wax. The activation energy calculated by Ozawa' method has the same rule. On the contrary, the activation energy of pure HMX almost has no change comparing with the formulation of HTW. However, the value of $E_{\text {a }}$ remarkably decries about $20 \%$ without the paraffin wax. These results suggest that the addition of wax could improve the thermal stability for the formulation of TKX-50, but the wax plays an opposite role in the formulation of HMX.

\subsection{The specific heat capacity of formulations}

Fig. 7 shows the determination results of specific heat capacity of four formulations using DSC (NETZSCH Company). The

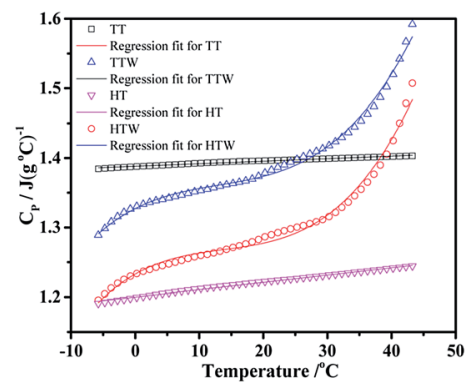

Fig. 7 Specific heat capacity of four formulations as a function of temperature.

heating rate was $10{ }^{\circ} \mathrm{C} \mathrm{min}^{-1}$ and temperature range is from -5 to $45{ }^{\circ} \mathrm{C}$. In determined temperature range, the specific heat capacity of four formulations presents a good relationship with temperature. Both the correlation coefficient and the regression equation of the four formulations were shown in Table 2. So the resulted specific capacity of TT, TTW, HT and HTW is $1.40 \mathrm{~J}$ $\left(\mathrm{g}^{-1}{ }^{\circ} \mathrm{C}\right), 1.42 \mathrm{~J}\left(\mathrm{~g}^{-1}{ }^{\circ} \mathrm{C}\right), 1.23 \mathrm{~J}\left(\mathrm{~g}^{-1}{ }^{\circ} \mathrm{C}\right)$ and $1.21 \mathrm{~J}\left(\mathrm{~g}^{-1}{ }^{\circ} \mathrm{C}\right)$ at $25^{\circ} \mathrm{C}$ respectively.

The explosives generated hot-spots under the mechanical treatment, where the detonation come from..$^{31,32}$ From the Fig. 7, we can see the specific heat capacity TKX-50 based explosives have a better heat absorption capacity comparing with HMX based explosives at room temperature. In another word, the TKX-50 based formulations can absorb more heat and reduce the temperature of the hot-spots, so that the explosive selfaccelerating reaction is prevented and the probability of

Table 1 Activation energy and pre-exponential factor evaluation by Kissinger and Ozawa method of the four formulations

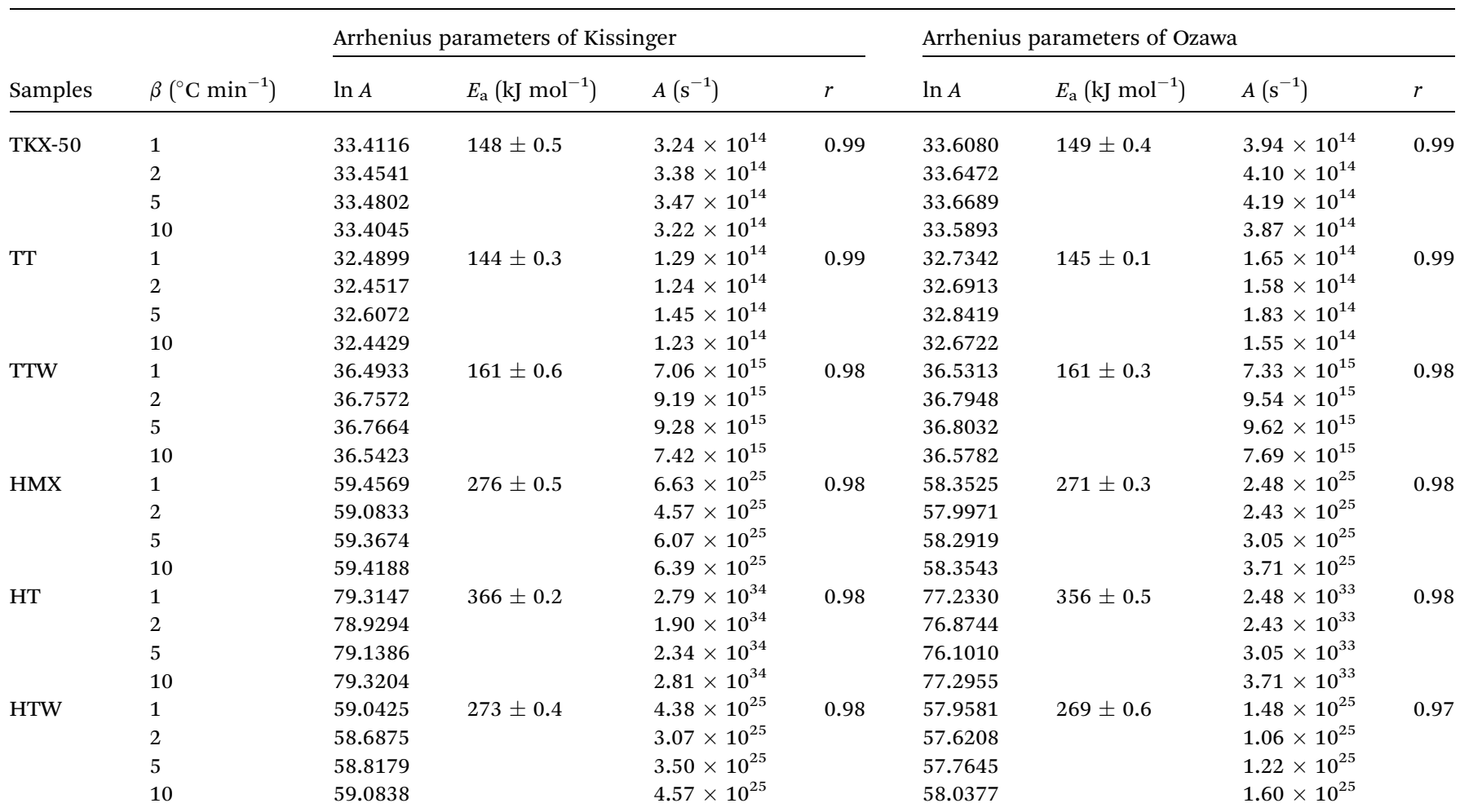


Table 2 The regression equations of four formulations

\begin{tabular}{lll}
\hline Sample & Regression equation & $R^{a}$ \\
\hline TT & $C_{\mathrm{p}}=1.39+3.64 \times 10^{-4} T$ & 0.99 \\
TTW & $C_{\mathrm{p}}=1.32+4.70 \times 10^{-3} T$ & 0.99 \\
& $-2.41 \times 10^{-4} T^{2}+6.11 \times 10^{-6} T^{3}$ & \\
HT & $C_{\mathrm{p}}=1.20+1.05 \times 10^{-3} T$ & 0.99 \\
HTW & $C_{\mathrm{p}}=1.23+5.23 \times 10^{-3} T$ & 0.99 \\
& $-2.91 \times 10^{-4} T^{2}+7.02 \times 10^{-6} T^{3}$ & \\
${ }^{a}$ Correlative coefficient. &
\end{tabular}

chemical reaction at the hot spot is reduced. Consequently, the TKX-50 based explosives are more insensitive under the impact (see in next section).

The specific heat capacity of TT and HT formulations have a good linear relationship with temperature and that of TTW and HTW formulations are cubic relationship as shown in Table 2 . In the temperature range of $5-30{ }^{\circ} \mathrm{C}$, both the four formulations have little change with the increasing temperature. However, that of the formulations TTW and HTW appeared significantly increased during the $30{ }^{\circ} \mathrm{C}$ to $45{ }^{\circ} \mathrm{C}$, which is resulted from the addition of wax. The wax is gradually softened as the temperature increased, which is an endothermic process. So the specific heat capacity is rising up sharply.

\subsection{Safe properties and detonation performance}

The results of the characteristics determined for the four formulations are given in Table 3. The VODs of HMX based formulation HT were found to be lower than that for the TKX-50 based formulations TT. As expected the VODs of wax mixtures were lower than those of the non-wax mixtures. The VOD of formulation HTW is also lower than that for the formulation TTW. An optimization of the process parameters of the compositions should bridge the gap in VODs of the non-wax formulations. Despite having lower VODs, waxed, TNT-based, melt cast high explosive compositions find application as high explosive fillings in various blast warheads and projectiles due to the overall enhanced energy release over an extended time.

The sensitivity data of an explosive composition plays a vital role in its use in armaments and gives an indication about safe hazards related its handling and storage. The impact sensitivity $\left(H_{50}\right)$ of TT and TTW are $63 \mathrm{~cm}$ and $66 \mathrm{~cm}$, respectively, which is higher than that of HT and HTW. In another words, the TKX-50

Table 3 Energy and sensitivity parameters of formulations

\begin{tabular}{llllll}
\hline Sample & $\operatorname{VOD}^{a}\left(\mathrm{~m} \mathrm{~s}^{-1}\right)$ & $P^{b}(\mathrm{GPa})$ & $\mathrm{IS}^{c}(\mathrm{~cm})$ & $\operatorname{VST}^{d}\left(\mathrm{~mL} \mathrm{~g}^{-1}\right)$ & $\operatorname{DET}^{e}\left({ }^{\circ} \mathrm{C}\right)$ \\
\hline TT & 8539 & 31.54 & 63 & 0.12 & 312.17 \\
HT & 8268 & 29.78 & 40 & 0.39 & 317.57 \\
TTW & 8265 & 27.09 & 66 & 0.27 & 313.29 \\
HTW & 8015 & 25.64 & 46 & 0.12 & 310.09
\end{tabular}

${ }^{a}$ Velocity of detonation. ${ }^{b}$ Detonation pressure. ${ }^{c}$ Impact sensitivity.

${ }^{d}$ Vacuum stability test. ${ }^{e} 5 \mathrm{~s}$ delay explosion temperature. based melt cast formulations are found to be more insensitive on impact. Furthermore, the thermal stability of sample is qualified, when the value of VST is less than $2.0 \mathrm{~mL} \mathrm{~g}^{-1}$, according to the stability evaluation standard GJB 772A-97. In another word, all of the four formulations have a good thermal stability. In addition, the $5 \mathrm{~s}$ delay explosion temperature values of these formulations are both above $310{ }^{\circ} \mathrm{C}$, so the four formulations have a good stability. However, from the detonation data, we can see that the TKX-50 based formulations have better energetic performance than that of HMX formulations.

In a word, the comprehensive performance (energy and safety) of TKX-50 based melt cast compositions TT and TTW are superior to the HMX based compositions HT and HTW.

\subsection{Theoretical studies}

In the context of melt-cast explosives, primarily three different forces, viz., van der Waals, electrostatic forces and hydrogen interaction energies. These forces may be reflected by the interaction energy. Interaction energies are calculated at B3LYP/ 6-311G** level by Gaussian 09. From Fig. 8 it is clear that TKX50-TKX-50 interactions are much stronger owing to its profound intra and intermolecular interactions than HMXHMX. Hence, the energies of explosive particle-particle interactions are higher in TKX-50 than HMX. While analysing the dispersant-particle interaction, TKX-50-TNT is slightly higher than HMX-TNT, because it is obvious to expect higher yield value in TKX-50-TNT due to the strong dispersant-particle interaction forces. Molecular electrostatic potential (MEP) is used commonly in analyzing interactions and is useful in providing information about local polarity due to the charge

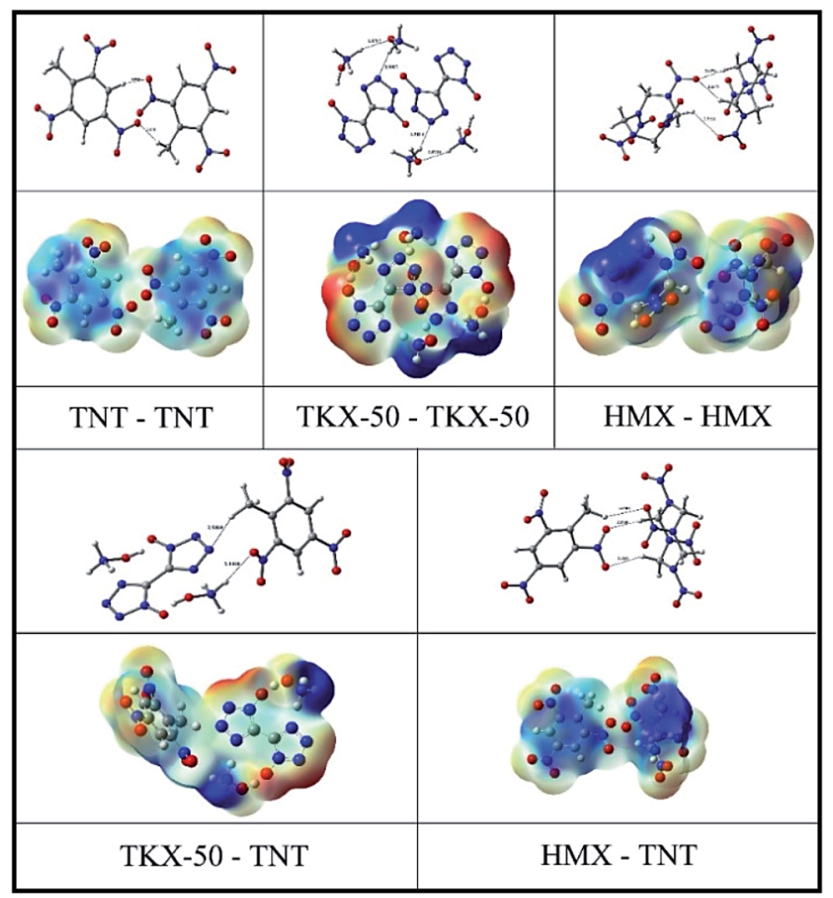

Fig. 8 MEP for the 0.001 electron bohr $^{-3}$ isosurface of electron density for the studied systems along with their molecular structure. 


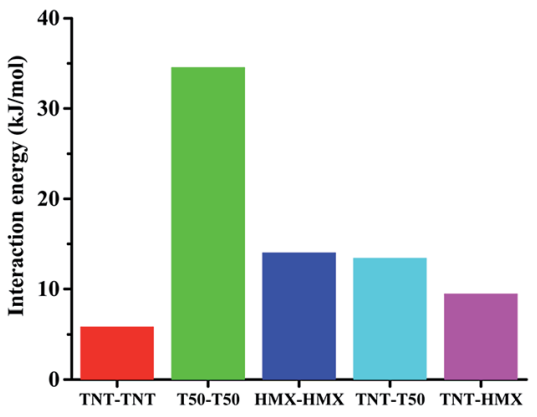

Fig. 9 Calculated interaction energy of various compounds under study.

density distribution. Fig. 8 illustrates the MEP for the 0.001 electron bohr ${ }^{-3}$ isosurface of electron density for the studied systems along with their molecular structure. The color range from -30 to $+30 \mathrm{kcal} \mathrm{mol}^{-1}$, with red denoting the most negative potential and blue denoting the most positive potential. Comparing the bond distance between hydrogen and oxygen of adjacent molecule clearly demonstrates the extent of interaction. Distance between hydrogen and oxygen of TKX-50-TNT is lower than the HMX-TNT. Overall, it is clear from the interactions study that stronger attractive forces exist in TKX-50-TKX50 than HMX-HMX pairs and similarly in TKX-50-TNT than HMX-TNT, as shown in Fig. 9. Hence, it is obvious to expect a higher binding ability of TKX-50-TNT than HMX-TNT, which has a good agreement with the SEM pictures. In the present study it is established the influence of the explosive molecular coating with TNT or TNT/WAX over intra/intermolecular interactive forces in determining the extent of coating.

Presently, large scale evaluation of TKX-50/TNT (60/40) meltcast formulations is made firstly and it is proven to be very successful in achieving impact insensitive compositions better than HMX/TNT. In a word, this study finds useful in realizing higher performance TKX-50/TNT compositions than HMX/TNT in energy and safety.

\section{Conclusions}

Dihydroxylammonium 5,5'-bistetrazole-1,1'-diolate (TKX-50) based melt cast formulations were prepared using TNT as a dispersant and studied the thermal decomposition kinetics by differential scanning calorimetry indicate a greater thermal stability of formulations TKX-50/TNT and TKX-50/TNT/WAX compared to HMX/TNT and HMX/TNT/WAX. Impact sensitive measurements of TKX-50 based, melt cast compositions are superior to the corresponding HMX based compositions. The VODs of TKX-50 based formulations have higher performance than that of HMX based formulations.

In order to get more insight on coating mechanism, the interaction energies are calculated at B3LYP/6-311G** level, which reveal that stronger attractive forces exit in TKX-50-TKX50 pairs than HMX-HMX pairs and similarly in TKX-50-TNT than HMX-TNT. The intermolecular interactive forces are the main factors affect the coating conditions of these formulations. This comparative study establishes interactive forces have a good agreement with coating conditions in the melt cast formulations and reveals that the safe and energy performance of TKX-50 based formulations is superior to HMX based formulations.

Initial studies indicate the potential of TKX-50 as a replacement for HMX in TNT based melt cast formulations to achieve low vulnerability with little sacrifice in performance.

\section{Acknowledgements}

We acknowledge the financial support from the Youth Innovation Fund of the North Chemical Industry Group (No. 3090041410054) and the Excellent Young Scholar Research Found of Beijing Institute of Technology of China (No. 3090012331542).

\section{References}

1 E. C. Koch, Propellants, Explos., Pyrotech., 2015, 40, 374.

2 Z. Liu, Q. Wu, W. Zhu and H. Xiao, Phys. Chem. Chem. Phys., 2015, 17, 10568.

3 Z. Ma, B. Gao, P. Wu, J. Shi, Z. Qiao, Z. Yang, G. Yang, B. Huang and F. Nie, RSC Adv., 2015, 5, 21042.

4 R. B. Patel, V. Stepanov, S. Swaszek, A. Surapaneni and H. Qiu, Propellants, Explos., Pyrotech., 2015, 40, 210.

5 Q. Wu, L. Tan, Z. Hang, J. Wang, Z. Zhang and W. Zhu, RSC $A d v .$, 2015, 5, 93607.

6 J. Zhang, L. A. Mitchell, D. A. Parrish and J. M. Shreeve, J. Am. Chem. Soc., 2015, 137, 10532.

7 S. Taylor, E. Park, K. Bullion and K. Dontsova, Chemosphere, 2015, 119, 342.

8 N. Mark, J. Arthur, K. Dontsova, M. Brusseau and S. Taylor, Chemosphere, 2016, 144, 1249.

9 C. I. Olivares, C. D. S. Luna, J. Wang, J. A. Field, L. Abrell and R. Sierra-Alvarez, Chemosphere, 2016, 144, 1116.

10 J. C. Oxley, J. L. Smith, M. A. Donnelly, K. Colizza and S. Rayome, Propellants, Explos., Pyrotech., 2016, 41, 98.

11 A. Provatas and C. Wall, Propellants, Explos., Pyrotech., 2016, 41, 555.

12 M. E. Walsh, J. Energ. Mater., 2016, 34, 76.

13 T. M. Klapötke, N. Fischer, D. G. Piercey, J. r. Stierstorfe and M. Reymann, German patent, DE102011081254-A1, 2003.

14 (a) N. Fischer, D. Fischer, T. M. Klapötke, D. G. Piercey and J. Stierstorfer, J. Mater. Chem., 2012, 22, 20418; (b) J. L. Gottfried, T. M. Klapötke and T. G. Witkowski, Propellants, Explos., Pyrotech., 2017, 42, 353.

15 H. Huang, Y. Shi and J. Yang, J. Therm. Anal. Calorim., 2015, 121, 705.

16 N. Li, F. Zhao, Y. Luo, H. X. Gao, E. Yao, Z. Zhou, L. Xiao, R. $\mathrm{Hu}$ and H. Jiang, J. Therm. Anal. Calorim., 2015, 122, 1023.

17 B. Yuan, Z. Yu and E. R. Bernstein, J. Phys. Chem. A, 2015, 119, 2965.

18 V. P. Sinditskii, S. A. Filatov, V. I. Kolesov, K. O. Kapranov, A. F. Asachenko, M. S. Nechaev, V. V. Lunin and N. I. Shishov, Thermochim. Acta, 2015, 614, 85. 
19 Y. Yu, S. Chen, X. Li, J. Zhu, H. Liang, X. Zhang and Q. Shu, RSC Adv., 2016, 6, 20034.

20 H. Niu, S. Chen, Q. Shu, L. Li and S. Jin, J. Hazard. Mater., 2017, 338, 208.

21 S. Hu and S. Zhang, Chem. Propellants Polym. Mater., 2005, 3, 35.

22 H. E. Kissinger, Anal. Chem., 1957, 29, 1702.

23 T. Ozawa, J. Therm. Anal. Calorim., 1970, 2, 301.

24 H. J. Borchardt and F. Daniels, J. Am. Chem. Soc., 1956, 79, 41.

25 S. Vyazovkin, A. K. Burnham, J. M. Criado, L. A. PérezMaqueda, C. Popescu and N. Sbirrazzuoli, Thermochim. Acta, 2011, 520, 1.

26 V. D. Ghule, P. M. Jadhav, R. S. Patil, S. Radhakrishnan and T. Soman, J. Phys. Chem. A, 2010, 114, 498.

27 C. Zhang, J. Phys. Chem. B, 2007, 111, 14295.

28 M. J. Frisch, G. W. Trucks, H. B. Schlegel, G. E. Scuseria, M. A. Robb, J. R. Cheeseman, G. Scalmani, V. Barone, B. Mennucci, G. A. Petersson, H. Nakatsuji, M. Caricato, X. Li, H. P. Hratchian, A. F. Izmaylov, J. Bloino, G. Zheng, J. L. Sonnenberg, M. Hada, M. Ehara, K. Toyota,
R. Fukuda, J. Hasegawa, M. Ishida, T. Nakajima, Y. Honda, O. Kitao, H. Nakai, T. Vreven, J. A. Montgomery Jr, J. E. Peralta, F. Ogliaro, M. Bearpark, J. J. Heyd, E. Brothers, K. N. Kudin, V. N. Staroverov, R. Kobayashi, J. Normand, K. Raghavachari, A. Rendell, J. C. Burant, S. S. Iyengar, J. Tomasi, M. Cossi, N. Rega, J. M. Millam, M. Klene, J. E. Knox, J. B. Cross, V. Bakken, C. Adamo, J. Jaramillo, R. Gomperts, R. E. Stratmann, O. Yazyev, A. J. Austin, R. Cammi, C. Pomelli, J. W. Ochterski, R. L. Martin, K. Morokuma, V. G. Zakrzewski, G. A. Voth, P. Salvador, J. J. Dannenberg, S. Dapprich, A. D. Daniels, O. Farkas, J. B. Foresman, J. V. Ortiz, J. Cioslowski and D. J. Fox, Gaussian, Inc., Wallingford CT, 2009.

29 C. I. Braga, M. C. Rezende and M. L. Costa, J. Aerosp. Technol. Manage., 2001, 3, 179.

30 N. Sasidharan, B. Hariharanath and A. G. Rajendran, Thermochim. Acta, 2011, 520, 139.

31 R. C. Bowers, J. B. Romans and W. A. Zisman, Ind. Eng. Chem. Prod. Res. Dev., 1973, 12, 2.

32 J. L. Copp, S. E. Napier and T. Nash, Philos. Trans. R. Soc., A, 1948, 24, 197. 